\title{
How Do Biota Respond to Additional Physical Restoration of Restored Streams?
}

\author{
Christer Nilsson, ${ }^{1 *}$ Judith M. Sarneel, ${ }^{1,2}$ Daniel Palm, ${ }^{3}$ \\ Johanna Gardeström, ${ }^{1}$ Francesca Pilotto, ${ }^{1}$ Lina E. Polvi, ${ }^{1}$ Lovisa Lind,${ }^{1}$ \\ Daniel Holmqvist, ${ }^{4}$ and Hans Lundqvist ${ }^{3}$
}

${ }^{1}$ Landscape Ecology Group, Department of Ecology and Environmental Science, Umea University, 90187 Umeå, Sweden; ${ }^{2}$ Ecology $\&$ Biodiversity Group and Plant Ecophysiology Group, Utrecht University, Padualaan 8, 3584 CH Utrecht, The Netherlands; ${ }^{3}$ Department of Wildlife, Fish and Environmental Studies, Swedish University of Agricultural Sciences, 90187 Umeå, Sweden; ${ }^{4}$ Ume/Vindel River Fishery Advisory Board, c/o Lycksele Municipality, 92181 Lycksele, Sweden

\begin{abstract}
Restoration of channelized streams by returning coarse sediment from stream edges to the wetted channel has become a common practice in Sweden. Yet, restoration activities do not always result in the return of desired biota. This study evaluated a restoration project in the Vindel River in northern Sweden in which practitioners further increased channel complexity of previously restored stream reaches by placing very large boulders $(>1 \mathrm{~m})$, trees $(>8 \mathrm{~m})$, and salmonid spawning gravel from adjacent upland areas into the channels. One reach restored with basic methods and another with enhanced methods were selected in each of ten different tributaries to the main channel. Geomorphic and hydraulic complexity was enhanced but the chemical composition of riparian soils and the communities of riparian plants and fish did not exhibit any clear responses to the enhanced
\end{abstract}

restoration measures during the first 5 years compared to reaches restored with basic restoration methods. The variation in the collected data was among streams instead of between types of restored reaches. We conclude that restoration is a disturbance in itself, that immigration potential varies across landscapes, and that biotic recovery processes in boreal river systems are slow. We suggest that enhanced restoration has to apply a catchment-scale approach accounting for connectivity and availability of source populations, and that low-intensity monitoring has to be performed over several decades to evaluate restoration outcomes.

Key words: fish; geomorphic complexity; hydraulics; ice; landscape scale; restoration; riparian chemistry; riparian plants; Sweden.
Received 16 January 2016; accepted 31 May 2016; published online 3 August 2016

Electronic supplementary material: The online version of this article (doi:10.1007/s10021-016-0020-0) contains supplementary material, which is available to authorized users.

Author contributions $\mathrm{CN}$ and HL conceived of and designed the study and wrote the paper; JMS, DP, LEP and LL designed the study, performed research, analyzed data and wrote the paper; FP and JG analyzed data and wrote the paper; DH designed the study.

*Corresponding author; e-mail: christer.nilsson@umu.se

\section{INTRODUCTION}

Restoration of deteriorated streams and rivers aims to improve biodiversity, recreation, and mitigation of impacts from direct anthropogenic alterations and climate change. The development of restoration methods is currently getting a boost, as it is supported by national and international directives (Bullock and others 2011; Aronson and Alexander 
2013; Pander and Geist 2013). Recent findings, that stream restoration is economically profitable (Acuna and others 2013), may further contribute to its development. The increase in different ways to restore streams and rivers is also clearly reflected in a steadily increasing number of scientific papers reporting on their results. For example, a recent (27 April 2016) search for '(stream* OR river*) AND restoration' in the Core Collection of Web of Science generated 9134 hits and the number of papers quadrupled between years 2000 and 2014. Although most stream restoration projects are completed without or with very little evaluation of the outcome (Kondolf and Micheli 1995; Bernhardt and others 2005; Suding 2011), the growing body of literature and initiatives such as RiverWiki (2014) have expanded the knowledge about how restoration measures should be designed to be effective (for example, Alexander and Allan 2007; Kail and others 2007; Jähnig and others 2010; Palmer and others 2010; Fryirs and others 2013; Nilsson and others 2015; Wohl and others 2015). Streams can now be restored more effectively than just a few decades ago, but there is certainly room for further improvements.

Hitherto, most restoration projects have been onetime-events, irrespective of the nature of results achieved in any follow-up studies. At best, new restoration projects have applied knowledge gained from previous studies and applied a modified design. For that to happen, however, close engagement with managers is required rather than publication of scientific papers (Bernhardt and others 2007; Wohl and others 2015). There are also examples of when restoration practices have been redesigned because of changing climatic conditions, that is, "adaptive restoration" in response to a moving target (Zedler 2010; Nungesser and others 2015). Another strategy would be "additional restoration," which can mean: (1) increasing the area of restored habitat to improve the responses of the originally restored area (for example, Krause and Culmsee 2013; Conlisk and others 2014), (2) connecting the restored site to other restored sites (Aviron and others 201 1; Crouzeilles and others 2014), or (3) returning to the restored site before it has fully recovered to make further adjustments based on new knowledge of the design and outcomes of monitoring (for example, Harms and Hiebert 2006; van Dijk and others 2007; Jiménez and others 2015). This paper will deal with the third of these strategies.

Over more than a century, streams and rivers in many boreal regions have been successively straightened and simplified and even dammed to facilitate the floating of logs-a procedure summarized as channelization (Törnlund and Östlund
2002). In a stream restoration project that started in northern Sweden in 2002, practitioners restored streams that were previously channelized for timber-floating, while scientists described the previously used floatway structures and their geomorphic impacts, predicted environmental outcomes of restoration, and studied the biotic effects of this and even earlier restoration projects (Nilsson and others 2005a). The return of coarse sediment formerly extracted from the channel, reopening of closed side channels and removal of splash dams made the restored reaches more complex with wider channels and increased floodplain connectivity (Polvi and others 2014). Follow-up studies of in-stream organisms 3-8 years after restoration, however, showed only very modest recovery of macroinvertebrates and fish (Lepori and others 2005, 2006). Recent studies have shown that for riparian vegetation it can take at least 25 years until its status even resembles that of channelized reaches, where restoration is a disturbance that vegetation has to recover from (Hasselquist and others 2015), although there are local exceptions where riparian plants respond faster (Helfield and others 2007).

The slow or absent biotic response to restoration measures fostered the idea that the physical modifications were not strong enough and that further addition of spawning gravel, big boulders, and large wood would improve the biotic recovery (Palm and others 2007; Rosenfeld and others 2011). This idea was based on the hypothesis that habitat heterogeneity favors biodiversity (Ward and Tockner 2001; Tews and others 2004; Elosegi and others 2010). A more recent stream restoration project in northern Sweden which began in 2010 (www. vindelriverlife.se) gave practitioners an opportunity to apply such enhanced restoration techniques. They returned to some of the previously restored sites and carried out the suggested additional measures aimed at increasing geomorphological and hydraulic complexity even more, thus paving the way for an enhancement of retention capacity, habitat heterogeneity, and potentially biodiversity (see further Gardeström and others 2013). We formed a team of natural scientists, with expertise in hydraulics, geomorphology, riparian soil chemistry, plant ecology and fish ecology and studied the environmental outcomes of these enhanced restoration techniques during 5 years. The major scientific objective was to test whether the biotic response to enhanced restoration methods was different than the response to the original, more basic methods. We hypothesized that enhanced restoration of basic-restored stream reaches would 
increase complexity and lead to increased biotic diversity for different species groups (fish and plants).

\section{STUdy Sites}

The Vindel River is a free-flowing river system (Dynesius and Nilsson 1994; Nilsson and others 2005b), which flows southeast from the border between Norway and Sweden for $450 \mathrm{~km}$ and joins the heavily regulated Ume River $30 \mathrm{~km}$ upstream of the Gulf of Bothnia. The Vindel River catchment comprises $12,654 \mathrm{~km}^{2}$, and $5 \%$ of this area is lakes that commonly link tributary stream segments. The region receives $500-850 \mathrm{~mm}$ of precipitation per year, $40 \%$ of which is snow (SMHI 2013). The area experiences a mean annual air temperature between 2 and $4^{\circ} \mathrm{C}$ with the highest mean monthly temperature in July $\left(10-15^{\circ} \mathrm{C}\right)$ and the lowest in January ( -9 to $-15^{\circ} \mathrm{C}$ ) (SMHI 2010), leading to accumulation of snow and ice during winter and large seasonal variations in discharge.

The Vindel River and its tributaries cross the highest postglacial coastline at $240 \mathrm{~m}$ above the present sea level along the lower middle parts of the catchment. This former coastline separates glaciated areas from land that has been under sea level and rose because of postglacial isostatic rebound (Lambeck and others 1998). The channel bed sediment above the former highest coastline consists of undisturbed glacial legacy sediment, whereas below there is finer sediment, containing silt and sand, in addition to gravel, cobbles, and boulders. The tributary streams mainly have snowmelt-dominated floods and lack the ability to transport coarse glacial legacy sediment. This makes these streams quite unique in their structural complexity of somewhat randomly sorted large boulders. The tranquil reaches and lakes, which alternate with the rapids, can have a variety of substrates but in most cases have a large proportion of finer sediments such as sand and silt.

The riparian vegetation surrounding the tributary streams is distinctly vertically zoned from the hillslope to the channel, ranging from conifer forest at the highest elevations, followed by shrubs, graminoids and amphibious plant communities closest to the water edge (Nilsson and others 1994). The widths of the vegetation zones are determined by hydrological conditions, with the upper end of riparian vegetation reflecting the spring-flood peak level, whereas the lower end of the vegetation zone is determined by average summer low water levels (Nilsson and others 1994). Understory vegetation of adjacent uplands is dominated by species-poor communities of dwarf shrubs. The average length of the annual growing season (days when the average temperature exceeds $+5^{\circ} \mathrm{C}$ ) ranges between 105 and 190 days, depending on geographic position. The fish fauna in the Vindel River is characterized by anadromous Salmo salar (Atlantic salmon) and both anadromous and resident $S$. trutta (brown trout). Spawning of $S$. salar only occurs in the main channel of the Vindel River, whereas $S$. trutta spawn throughout the system. Juvenile $S$. salar, hatched in the main channel, ascend tributaries to use them as nursery habitat. The tributary streams also contain populations of Thymallus thymallus (European grayling), Esox lucius (northern pike), Perca fluviatilis (European perch), Phoxinus phoxinus (common minnow), Cottus gobio (European bullhead), and Lota lota (burbot).

From the mid-1800s to 1976, the Vindel River waterways were used for timber floating. During this period, nearly all turbulent reaches below timberline were channelized to facilitate the transportation of logs (Törnlund and Östlund 2002; Nilsson and others 2005a). Channelization disrupted the clear plant zonation and led to lower cover and species richness of plants (Helfield and others 2007). It also harmed many of the valued fish populations, and therefore, restoration was initiated after timber floating was replaced by road transport. Some restoration was done already in the 1980s and 1990s, but it was not until 2002 that a more ambitious restoration project started that aimed to bring the channels and their fish populations back to more pristine states (Nilsson and others 2005a; Gardeström and others 2013). Although the prime interest was to restore fish populations, awareness grew that the riparian plant communities and soil processes within the riparian zone are also important to restore, as the riparian zone is a biodiversity hotspot in the landscape and plays an important role in modifying cycles and fluxes of sediment, nutrients and organisms (Naiman and Décamps 1997; Naiman and others 2005).

\section{MethodS}

\section{Study Sites}

The study was carried out in 10 tributaries of the Vindel River (Figure 1; Online Appendix 1), in which pairs of reaches restored in the early 2000s were selected. One reach in each pair was subjected to enhanced restoration in 2010 (Figure 2, Online Appendix 1). This restoration entailed that, in addition to the original restoration in which coarse sediment was returned from the channel edges to 


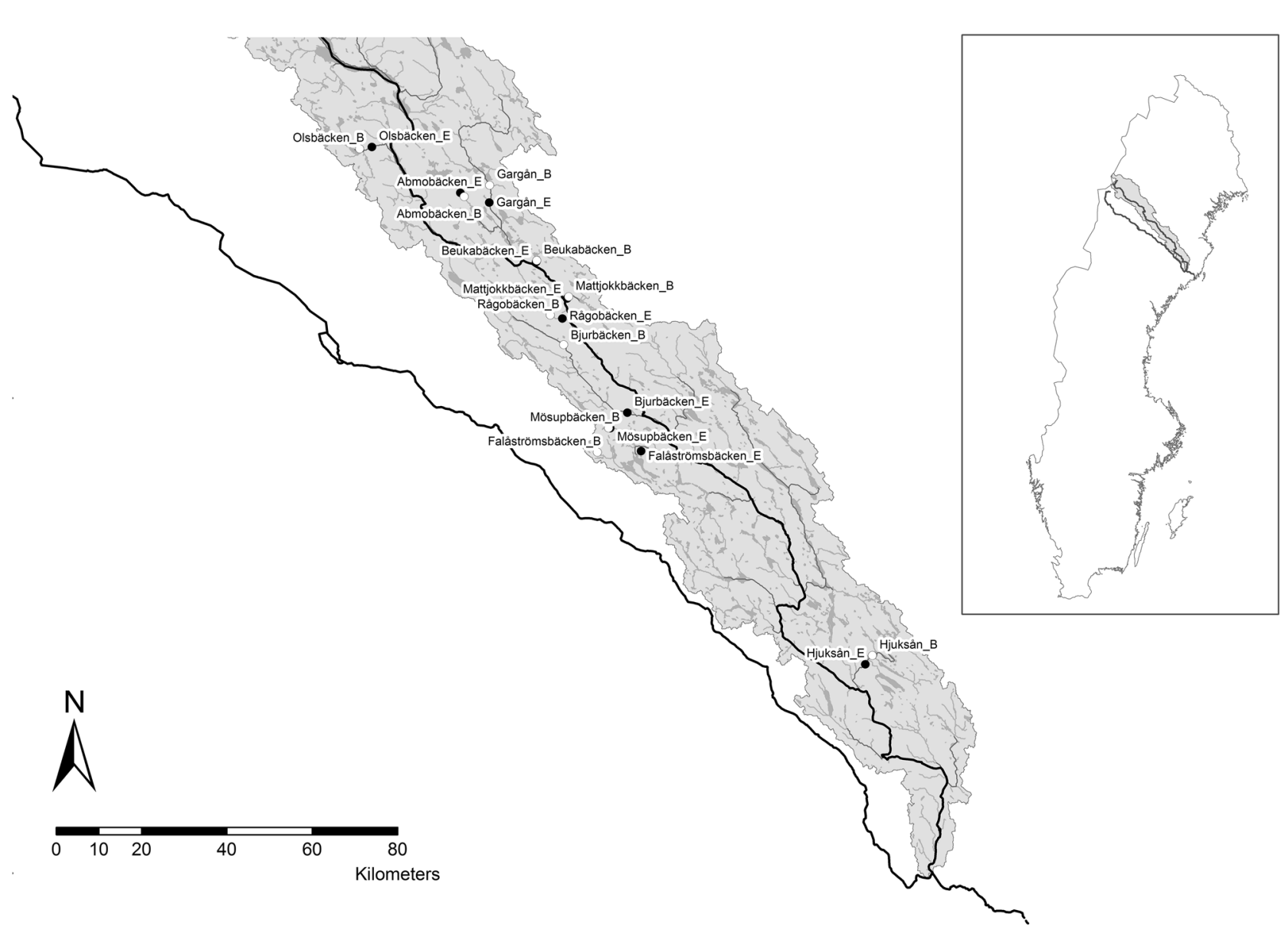

Figure 1. Map of the Vindel River catchment (gray), showing location of study reaches on tributaries to the Vindel River (thick black line); lakes are shown as darker gray polygons. The black line outside of the Vindel River catchment denotes the Ume River. Inset map shows the location of the Vindel River catchment and the Vindel and Ume Rivers within Sweden.

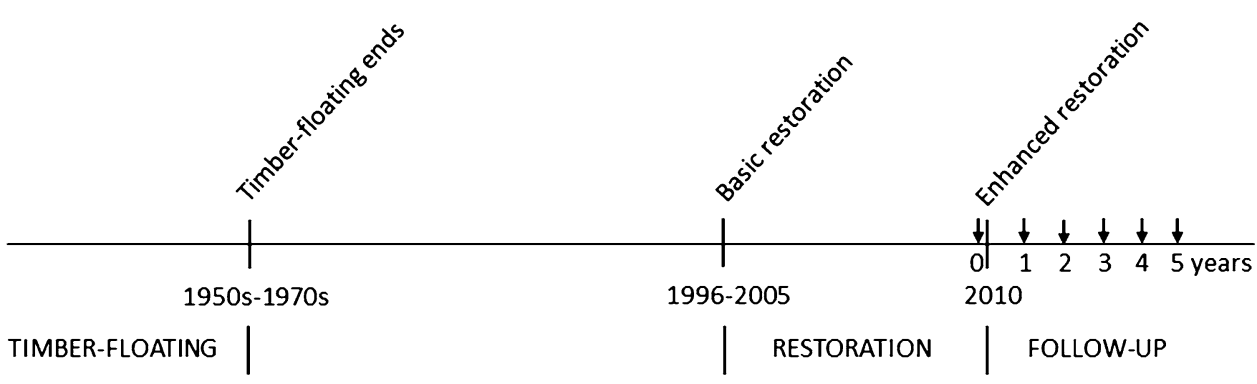

\begin{tabular}{|c|c|c|c|c|c|c|}
\hline $\begin{array}{c}\text { Monitoring } \\
\text { years }\end{array}$ & Hydraulics & Ice & Geomorphology & $\begin{array}{l}\text { Riparian soil } \\
\text { chemistry }\end{array}$ & Plants & Fish \\
\hline 2010 & $x$ & & & & & $x$ \\
\hline 2011 & $x$ & $x$ & & & & \\
\hline 2012 & & $x$ & $x$ & & & \\
\hline 2013 & & & & $x$ & $x$ & \\
\hline 2014 & $x$ & & & $x$ & $x$ & \\
\hline 2015 & & & & & & $x$ \\
\hline
\end{tabular}

Figure 2. Timeline showing the sequence of timber-floating and restoration periods and the period of follow-up work preceding and following the restoration. A pre-restoration monitoring event took place directly before the enhanced restoration, followed by postrestoration monitoring 1 , $2,3,4$, and 5 years after enhanced restoration. Note that all variables were not monitored every year. 
the channel, very large boulders $(>1 \mathrm{~m})$ and trees $(>8 \mathrm{~m})$ from surrounding areas were placed in the streams as a replacement for the boulders that had been fragmented by explosives. Gravel from external sources was also added to create spawning habitat for $S$. trutta, because original spawning sediment had been removed due to higher velocities after channelization (Gardeström and others 2013). We consistently call these two types of restoration "basic restoration" and "enhanced restoration" (Figure 3). These terms refer to the same types of restoration that Gardeström and others (2013), using EU LIFE terminology (http:// ec.europa.eu/environment/life/funding/life2015/), called "best-practice restoration" and "demonstration restoration".

Criteria used for selection of reaches for enhanced restoration were previous basic restoration, the presence of large boulders in the adjacent uplands and reasonably easy access for heavy machinery (Gardeström and others 2013). The basic-restored reach was located upstream to avoid influence from the disturbance of the enhanced restoration activities on the basic-restored reach. In seven of the streams, the reaches were located above and in three streams reaches were below the former highest coastline. Within each chosen restored reach, a 100-m long reach was selected for further study. Wetted width was measured at 10 cross sections and flow velocity and water depth were measured at five points across each of the 10 cross sections (50 measuring points) in each reach, following the methods described by Gardeström and others (2013). These measurements were made at low and medium flow conditions at three occasions: in 2010, before the enhanced restoration, and in 2011 and 2014, after the enhanced restoration (Figure 2). At each survey occasion discharge was also measured in each reach by measuring the cross-sectional area in a uniform cross section and velocity at 0.6 of the depth at $7-$ 11 points, depending on the wetted width. Mea-
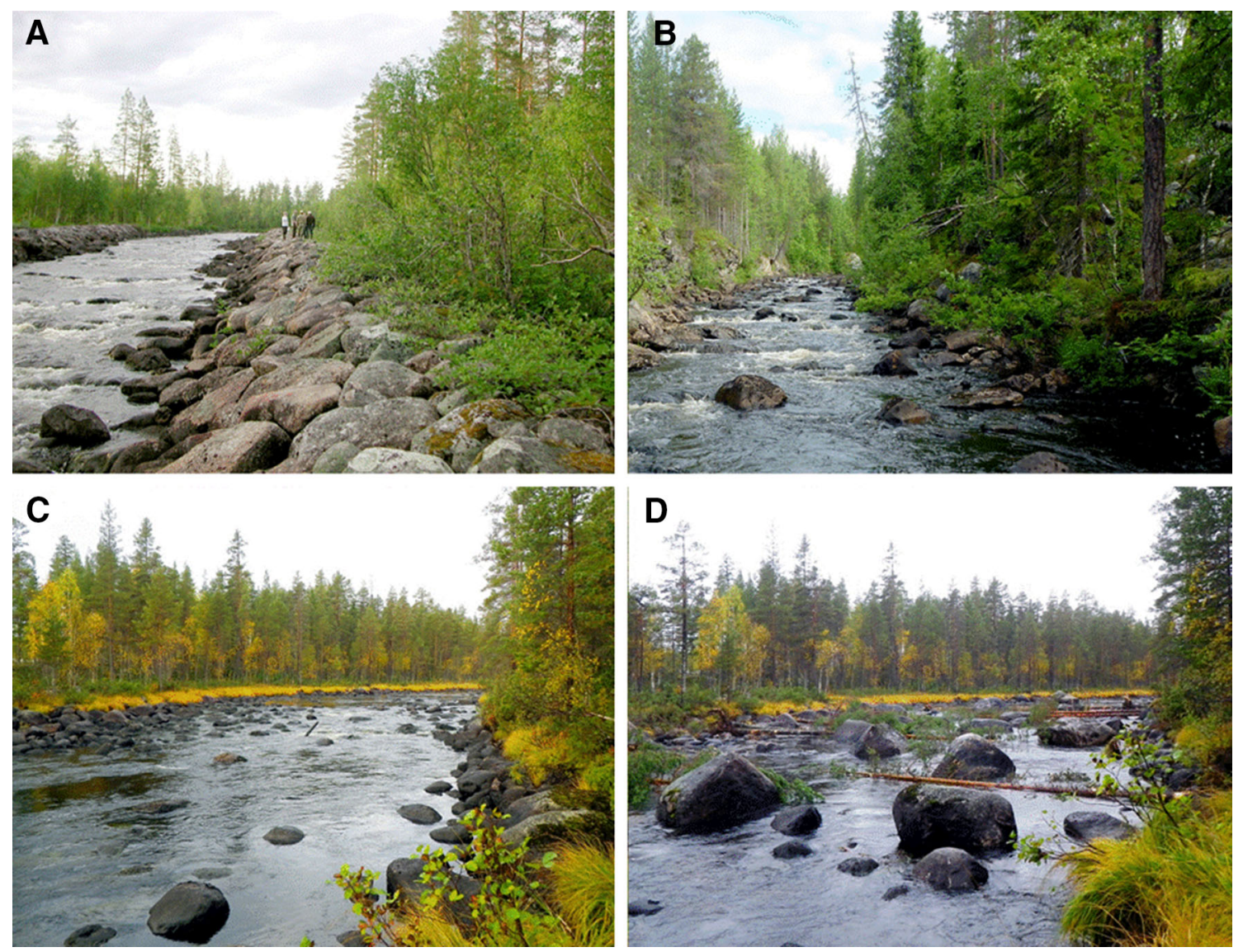

Figure 3. Pictures showing typical examples of the different types of reaches in the tributaries of the Vindel River. (A) A reach in Gargån channelized for timber-floating, (B) a reach in Mattjokkbäcken subjected to basic restoration in 2003 and no further restoration after that, $(\mathbf{C})$ a reach in Bjurbäcken subjected to basic restoration in 2002 and (D) the same reach as in $\mathbf{C}$ after enhanced restoration in 2010 . 
surements in the channel during high flow conditions were avoided for safety reasons. Channel bed slope $\left(\mathrm{S}_{0}\right)$ was measured in seven paired reaches with basic and enhanced restoration (Beukabäcken, Bjurbäcken, Falåströmsbäcken, Hjuksån, Mattjokkbäcken, Mösupbäcken, and Rågobäcken) using a total station (a Trimble S3 in 2012 and a Trimble S8 in 2015, with a Trimble TSC3 datalogger).

\section{Channel Bed Sediment}

A detailed survey of the channel bed sediment distribution was carried out at five paired reaches with basic restoration and enhanced restoration (Beukabäcken, Falåströmsbäcken, Mattjokkbäcken, Mösupbäcken, and Rågobäcken) in 2012, that is, 2 years after additional restoration (Polvi and others 2014). The intermediate axes of 300 clasts were measured along a random walk in equally spaced transects throughout the reach; for details on the survey method, see Polvi and others (2014). Based on the cumulative distribution curves of sediment grain sizes, the following metrics were computed: $\mathrm{D}_{10}, \mathrm{D}_{90}$, coefficient of variation and kurtosis. $\mathrm{D}_{10}$ and $\mathrm{D}_{90}$ are the 10th and 90th percentile of the cumulative grain size distribution and are descriptors of the fine and coarse fractions of the channel bed sediment. We computed the coefficient of variation of sediment (CV), which is a measure of the heterogeneity of the distribution (equation 1, Baker 2009).

$$
C V=\frac{\sqrt{\frac{D_{84}}{D_{16}}}}{D_{50}}
$$

where $\mathrm{D}_{16}, \mathrm{D}_{50}$, and $\mathrm{D}_{84}$ represent the median bed particle size corresponding to the various percentiles $(16 \%, 50 \%$, and $84 \%)$ of the particle size distributions. They roughly correspond to the distribution of fines $\left(D_{16}\right)$, median $\left(D_{50}\right)$, and coarse $\left(\mathrm{D}_{84}\right)$ materials. Kurtosis $(\mathrm{K})$ indicates the peakedness of distribution (Briggs 1977). High kurtosis values indicate a well-sorted sediment, and low kurtosis values indicate poorly sorted sediment (equation 2).

$$
K=\frac{D_{90}-D_{10}}{1.9\left(D_{75}-D_{15}\right)}
$$

\section{Hydraulics and Channel Roughness}

The analysis of the hydraulic data was performed separately for low and medium flow conditions and was carried out only for streams with complete datasets for both reach types and the three survey occasions ( $n=7$ as Abmobäcken, Gargån and Olsbäcken had incomplete datasets). For each reach, we computed Manning's $n$, which is a descriptor of channel roughness (equation 3 ).

$$
n=\frac{S^{1 / 2} R^{2 / 3} A}{Q}
$$

where $n$ is Manning's roughness coefficient, $S$ is the channel bed slope $\left(\mathrm{m} \mathrm{m}^{-1}\right), R$ is the hydraulic radius, calculated as the channel cross-sectional area $A\left(\mathrm{~m}^{2}\right)$ divided by the wetted perimeter $(\mathrm{m})$, and $Q$ is the discharge $\left(\mathrm{m}^{3} \mathrm{~s}^{-1}\right)$.

Because the hydraulic measurements taken at respective low and medium flows were relative to that year's hydrograph, the discharges were not the same at all low flows or all medium flows. Therefore, it was not possible to compare differences in hydraulic data (water depth and velocity) between years. To standardize the velocity measurements to make comparisons between years possible, we calculated a dimensionless velocity by standardizing the actual velocity by the shear velocity $\left(U^{*}\right)$ (equation 4).

$$
U^{*}=\sqrt{g R S}
$$

where $U^{*}$ is the shear velocity $\left(\mathrm{m} \mathrm{s}^{-1}\right), g$ is the acceleration due to gravity $\left(9.81 \mathrm{~m} \mathrm{~s}^{-2}\right), R$ is the hydraulic radius (m), and $S$ is the channel bed slope $\left(\mathrm{m} \mathrm{m}^{-1}\right)$.

The effect of enhanced restoration on Manning's $n$ and dimensionless flow velocity was tested by comparing values before enhanced restoration (year 2010) and those after enhanced restoration (years 2011, 2014, and combined 2011 and 2014) at each reach, with pairwise Student's $t$-tests. Similarly, pairwise Student's $t$ tests were also run for basic-restored reaches, where we did not expect differences between years. Although basic-restored reaches were paired with enhanced restoration reaches, comparisons between reaches with the two different types of restoration may not be valid because channel bed slopes differ substantially in some instances, which has a profound impact on hydraulic parameters.

\section{Ice Studies}

Along 10 cross sections at five paired reaches with basic and enhanced restoration, respectively (Beukabäcken, Falåströmsbäcken, Mattjokkbäcken, Mösupbäcken, and Rågobäcken), the spatial distribution of anchor ice, surface ice and specific ice forms and ice-related events (that is, anchor ice dams, aufeis and ice-induced floods) was mapped 
in 2011 and 2012. Anchor ice is usually initiated by the accumulation of tiny ice particles that have adhesive features in supercooled water and therefore attach to in-stream vegetation, coarse material and large wood (Stickler and Alfredsen 2009; Lind and others 2014a). Suspended ice is created when anchor ice dams collapse or when water recedes during winter, thereby leaving ice elevated above the water surface (Prowse 1995; Turcotte and Morse 2013). Ice formations were drawn on maps and photographed during field visits between six to nine times through November to April during the winters 2011-2012 and 2012-2013. Automatic Time Lapse Plant Cameras (Model WSCA04) were also placed at each reach and set to take three photographs per day (October-April), but they were not reliable in temperatures below $-15^{\circ} \mathrm{C}$ because of failing batteries. These photographs were used as complements to the visual mapping to follow ice dynamics between field visits. Ice data for the two winter seasons were quantified as mean proportions of suspended ice, surface ice and maximum anchor ice, respectively, in relation to the entire reach. Ice data and distance to upstream lakes were analyzed using ANOVA.

\section{Riparian Sampling}

For riparian abiotic and biotic variables, ten $0.5 \times 1 \mathrm{~m}$ plots were sampled per 100-m long reach. At every $10 \mathrm{~m}$ going downstream, one plot was placed at a different distances from the channel based on a random distribution applied at all reaches. The distance between each particular plot and the channel edge was determined as a percentage of the total width of the riparian zone, that is, distances ranged between $0 \%$ and $100 \%$. The lower border of the riparian zone was determined by the water level at the day of installing plots (in summer 2013), and the spring high-level was determined by eye as the transition from herb and grass vegetation to small shrubs and forest.

For each (riparian) sample location, the height relative to the water level was measured using a laser pointer and two level staffs. In all streams, water-level fluctuations were measured between October 2011 and August 2014 using Rugged TROLL pressure loggers (Amtele, Kungens Kurva, Sweden). Water level on the day of measurement and the water level fluctuations over time were used to calculate the average flooding duration and flooding frequency for each plot. For each reach, we also calculated the duration and depth of the spring flood as the number of days and the average depth when the water level was above the yearly average between April 1 and June 30 of that year. At each sampled plot, three to five soil cores were taken from the top $5 \mathrm{~cm}$ of the soil in August 2014. They were analyzed for plant available $\mathrm{N}$ following the Devarda's method (protocol SS-EN 15476:2009, Swedish Standard Institute, Stockholm) and plant available $\mathrm{P}$ after acid digestion with nitric acid (SS 028150-2), and an inductively coupled plasma-atomic emission spectrometry (ICP-AES) instrument enabling identification of low concentrations. Soil samples were shaken in demineralized water, leading to a suspension of solid material and a liquid phase consisting of dissolved substances from the soil. The soil organic content in the solid phase was determined by loss on ignition and $\mathrm{pH}$ was measured in the liquid phase.

The vegetation in the riparian zone was surveyed in August 2013 and 2014 in the ten $0.5 \times 1.0 \mathrm{~m}$ plots, before the soil samples were taken. The abundance of all plant species within the plots was determined using a 5 -class scale $(1=$ present with one individual and covering $<5 \%, 2=$ present with two or more individuals in $<5 \%, 3=5-25 \%$, $4=25-50 \%, 5=$ covering $>50 \%$ ). We also counted the number of seedlings per plot in August 2013 and 2014. In August 2014, the whole reach $(100 \mathrm{~m})$ was carefully searched and all species that were present in the entire reach were noted, including instream macrophytes but excluding bryophytes. Next to each vegetation plot, a $10 \times 10 \mathrm{~cm}$ plot was cut at soil level and dried to determine aboveground biomass of mosses and higher plants separately.

\section{Fish Sampling}

The number of fish species and salmonid densities were assessed in August 2010 and 2015 by electrofishing sites that had undergone basic and enhanced restoration in six streams (Olsbäcken, Abmobäcken, Beukabäcken, Mattjokkbäcken, Rågobäcken and Mösupbäcken) in three runs using a generator-powered electroshocker (Lugab, Luleå, Sweden) that produced a constant direct current of $800 \mathrm{~V}$. All fish collected were identified to species, counted, and measured (total length in $\mathrm{mm}$ ), before being returned to the water. Body mass of each individual of $S$. trutta and $S$. salar was obtained using a length-weight model developed for the study area (D. Palm, unpublished data). Fish density standardized for area was calculated using the methodology described by Zippin (1956). Fish biomass standardized for area was obtained by 
dividing the biomass caught during the first electrofishing run by the area of the sampled reach.

\section{Statistical Analyses for Biotic and Riparian Variables}

Data on flood dynamics, soil, vegetation, and fish metrics were compared among reach types and survey occasions using linear mixed models (LMM) (Nakagawa and Schielzeth 2010), performed with the R package "nlme" (Pinheiro and others 2015). LMMs included "reach type" (basic vs. enhanced restoration) and its interaction as fixed factors and "stream" as a random factor. By including "stream" as a random factor, we accounted for possible autocorrelations due to the spatial proximity of the reaches within the same stream and to the repeated-measure design of the study. As fish data were collected both before and after enhanced restoration, LMM on fish metrics included also "survey occasion" (before enhanced restoration vs. after enhanced restoration in 2011 and 2014) and its interaction with "reach type" as fixed factors.
Finally, "year" and its interaction with "reach type" were included as fixed factors in the LMM on flood data. Correlations among soil variables and between soil variables and seedling numbers were tested with Pearson's correlations.

\section{RESUlts}

\section{Abiotic Variables \\ Channel Bed Morphology}

Geomorphic, hydraulic, and ice variables showed a clear response to the enhanced restoration measures. The finer sediment size fraction (that is, $\mathrm{D}_{10}$ ) was smaller at the reaches with enhanced restoration in comparison with their respective basicrestoration reaches, with the exception of one stream (Mösupbäcken) where the same value was found at the two reach types (Figure 4A). Reaches with enhanced restoration also had coarser coarse fractions of channel bed sediments, with the exception of one stream (Beukabäcken) where the opposite was recorded (Figure 4B). This resulted in
D10

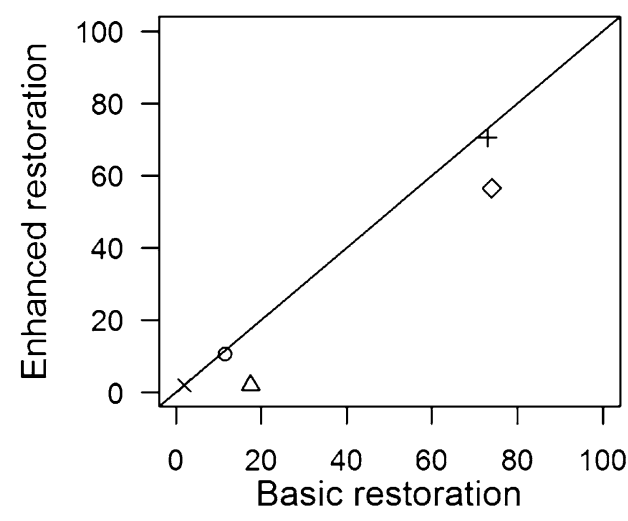

Coefficient of variation

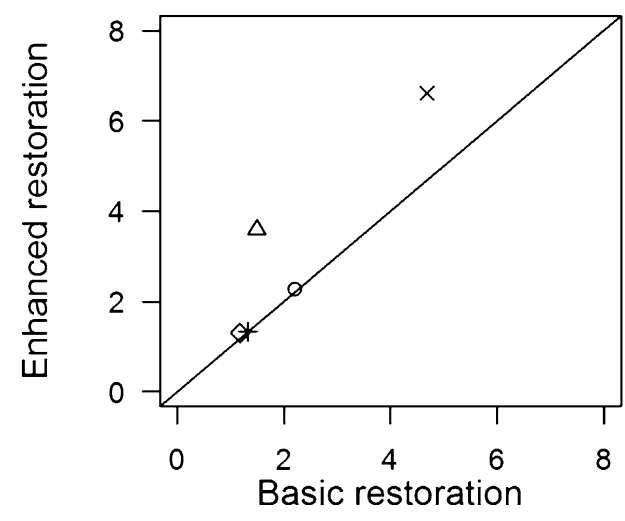

D90

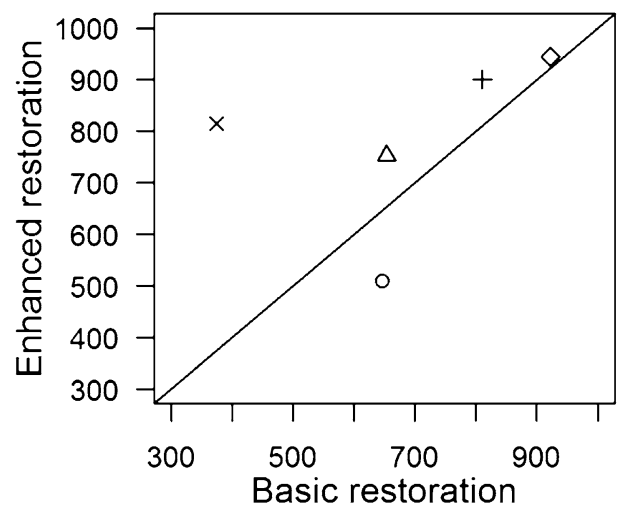

Kurtosis

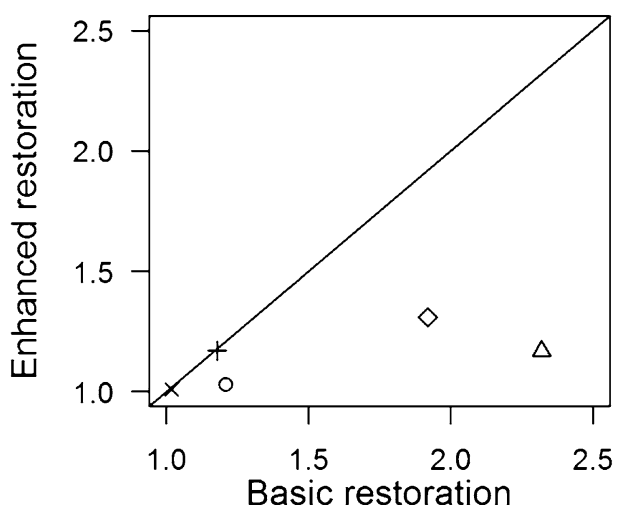

Figure 4. Channel bed sediment distribution. The location of each stream within the plot is based on the values recorded at reaches with basic restoration and enhanced restoration. Symbols on the bisector line indicate no differences between the two reach types, while symbols above the bisector line indicate higher values at reach with enhanced restoration than at the reach with basic restoration, and those below the bisector line indicate lower values at the reach with enhanced restoration than at the reach with basic restoration. See text for metric descriptions. 
a larger coefficient of variation and lower kurtosis of sediment distributions in reaches with enhanced restoration (Figure 4C, D), indicating higher heterogeneity of the sediment size distribution. The only exception to this general pattern was Mattjokkbäcken, where the coefficient of variation was the same at the two reach types.

Enhanced restoration significantly increased channel roughness, as quantified by Manning's $n$, and significantly decreased dimensionless flow velocities at both medium and low flow conditions (Table 1). On the contrary, at basic-restored sites, channel roughness and dimensionless flow velocity remained similar during the study period, with the exception of roughness, which was higher in 2014 than in 2010 at low flow condition, likely due to the particularly low discharges recorded that year (Table 2). There was a large difference in flow dynamics between years. Year 2012 had a higher spring flood compared to the other years (LMM, $\left.F_{1,46}=19.77, P<0.001\right)$. There was, however, no significant difference between restored reach types for the length or the stage of the spring flood, nor in the average amplitude of the water level fluctuations over the entire year. Because of their location further downstream, reaches with enhanced restoration had a wider wetted width and a higher discharge than basic-restored reaches at both flow conditions (Table 2).

Ice

There was no significant difference in the proportion of surface ice or suspended ice that was formed in the basic-restored and enhanced-restored reaches (Table 3). There was however a significant difference for the maximum per cent cover of anchor-ice formed between basic-restored and en-

Table 1. Changes in the Values of Manning's $n$ Roughness Coefficient and Dimensionless Flow Velocity (mean \pm SE) after Enhanced Restoration (Years 2011 and 2014) in Comparison to the Values Recorded Before Enhanced Restoration (2010), at Medium and Low Flow Conditions

\begin{tabular}{|c|c|c|c|c|}
\hline & \multicolumn{2}{|l|}{ Manning's $n$} & \multicolumn{2}{|c|}{ Dimensionless flow velocity } \\
\hline & Medium flow & Low flow & Medium flow & Low flow \\
\hline \multicolumn{5}{|l|}{ Enhanced restoration reaches } \\
\hline Change 2011-2010 & $0.04 \pm 0.01^{*}$ & $0.07 \pm 0.01 * *$ & $-0.71 \pm 0.21^{*}$ & $-0.38 \pm 0.06^{* *}$ \\
\hline Change 2014-2010 & $0.04 \pm 0.01^{*}$ & $0.12 \pm 0.03 * *$ & $-0.73 \pm 0.20 * *$ & $-0.50 \pm 0.05^{* *}$ \\
\hline $\begin{array}{l}\text { Change combined } 2011 \text { and 2014-2010 } \\
\text { Basic restoration reaches }\end{array}$ & $0.04 \pm 0.01^{* *}$ & $0.10 \pm 0.02 * *$ & $-0.72 \pm 0.18^{* *}$ & $-0.44 \pm 0.04^{* *}$ \\
\hline Change 2011-2010 & $-0.01 \pm 0.03 \mathrm{NS}$ & $0.04 \pm 0.02 \mathrm{NS}$ & $0.04 \pm 0.36 \mathrm{NS}$ & $0.17 \pm 0.10 \mathrm{NS}$ \\
\hline Change 2014-2010 & $-0.01 \pm 0.03 \mathrm{NS}$ & $0.06 \pm 0.02 *$ & $0.06 \pm 0.42 \mathrm{NS}$ & $-0.22 \pm 0.14 \mathrm{NS}$ \\
\hline Change combined 2011 and 2014-2010 & $-0.01 \pm 0.03 \mathrm{NS}$ & $0.04 \pm 0.01^{*}$ & $0.01 \pm 0.38 \mathrm{NS}$ & $-0.19 \pm 0.12 \mathrm{NS}$ \\
\hline
\end{tabular}

Statistical significance after pairwise Student's t test is shown $\left({ }^{* *} P<0.01,{ }^{*} P<0.05\right.$, NS $\left.P>0.05\right)$.

Table 2. Discharge and Wetted Channel Width (mean \pm SE) in the Reaches with Basic or Enhanced Restoration, in the Three Survey Occasions Before and After Enhanced Restoration at Low and Medium Flow

\begin{tabular}{|c|c|c|c|c|}
\hline & \multicolumn{2}{|c|}{ Discharge $\left(\mathrm{m}^{3} \mathrm{~s}^{-1}\right)$} & \multicolumn{2}{|c|}{ Wetted width (m) } \\
\hline & Low flow & Medium flow & Low flow & Medium flow \\
\hline \multicolumn{5}{|l|}{ Basic restoration } \\
\hline Before (2010) & $0.69 \pm 0.07$ & $1.17 \pm 0.09$ & $10.52 \pm 0.64$ & $11.82 \pm 0.70$ \\
\hline After (2011) & $0.63 \pm 0.09$ & $1.69 \pm 0.12$ & $10.31 \pm 0.63$ & $11.86 \pm 0.49$ \\
\hline After (2014) & $0.57 \pm 0.10$ & $1.33 \pm 0.16$ & $9.98 \pm 0.64$ & $11.53 \pm 0.54$ \\
\hline \multicolumn{5}{|c|}{ Enhanced restoration } \\
\hline Before (2010) & $1.42 \pm 0.17$ & $1.84 \pm 0.21$ & $12.60 \pm 0.76$ & $13.34 \pm 0.65$ \\
\hline After (2011) & $1.16 \pm 0.20$ & $2.78 \pm 0.34$ & $14.35 \pm 0.83$ & $14.29 \pm 0.57$ \\
\hline After (2014) & $1.03 \pm 0.20$ & $2.69 \pm 0.40$ & $14.05 \pm 0.82$ & $14.72 \pm 0.67$ \\
\hline
\end{tabular}


hanced-restored reaches as well as for the interaction between the type of restoration and the distance to upstream lakes (Table 3). There was also a significant relationship between the proportions of all types of ice formation (\%) and the distance to the upstream lake, with more ice forming further away from lake outlets (Table 3). Hence, most anchor ice was formed in reaches with enhanced restoration far away from upstream lakes.

\section{Riparian Soil Quality}

There was no significant difference in average $\mathrm{pH}$, amount of N, P, and organic content in the riparian soil between basic-restored reaches and enhanced reaches (Table 4). Instead, the observed variation in riparian chemistry occurred between streams (Online Appendix 2). Within the riparian zones, $\mathrm{pH}$ and moisture increased, and the organic content decreased with decreasing elevation (Table 4), and organic content was strongly correlated to the amounts of nutrients (Pearson's $r=0.677$, $P<0.001$ and $r=0.433, P<0.001$ for $\mathrm{N}$ and $\mathrm{P}$, respectively).

\section{Plants}

Plant species richness was lowest in plots close to the stream channel, then increased at elevations around 40 to $60 \mathrm{~cm}$ above the average water level, and decreased again at higher elevations. There was a slight trend towards higher plant species

Table 3. Formation of Surface Ice, Suspended Ice and Anchor Ice in Relation to Type of Restoration (Basic or Enhanced), Distance to Upstream Lakes and the Interaction Between Ice Type and Distance

\begin{tabular}{|c|c|c|c|c|}
\hline Ice formation & $\begin{array}{l}\text { Basic restoration } \\
\text { Mean } \pm \text { SE }\end{array}$ & $\begin{array}{l}\text { Enhanced restoration } \\
\text { Mean } \pm \text { SE }\end{array}$ & $F$ & $P$ \\
\hline \multicolumn{5}{|l|}{ Surface ice } \\
\hline Restoration & $19.18 \pm 0.38$ & $23.87 \pm 0.42$ & 0.76 & 0.49 \\
\hline Distance to lake & & & 14.80 & 0.001 \\
\hline Distance $\times$ restoration & & & 1.23 & 0.29 \\
\hline \multicolumn{5}{|l|}{ Suspended ice } \\
\hline Restoration & $8.48 \pm 0.33$ & $10.87 \pm 0.32$ & 1.47 & 0.24 \\
\hline Distance to lake & & & 86.60 & $<0.001$ \\
\hline Distance $\times$ restoration & & & 1.23 & 0.28 \\
\hline \multicolumn{5}{|l|}{ Maximum anchor ice } \\
\hline Restoration & $8.34 \pm 0.38$ & $21.6 \pm 0.44$ & 19.99 & 0.003 \\
\hline Distance to lake & & & 95.03 & $<0.001$ \\
\hline Distance $\times$ restoration & & & 6.33 & 0.023 \\
\hline
\end{tabular}

Table 4. Riparian Soil Quality (Nitrogen; N, Phosphorus; P, pH and Total Organic Content; TOC) and Flood Variables per Restoration Type

\begin{tabular}{lcc}
\hline Riparian variable & $\begin{array}{c}\text { Basic restoration } \\
\text { Mean } \pm \text { SE }\end{array}$ & $\begin{array}{c}\text { Enhanced restoration } \\
\text { Mean } \pm \text { SE }\end{array}$ \\
\hline $\mathrm{N}\left(\mathrm{g} \mathrm{kg}^{-1}\right)$ & $9.6 \pm 0.75$ & $9.9 \pm 0.85$ \\
$\mathrm{P}\left(\mathrm{g} \mathrm{kg}^{-1}\right)$ & $0.6 \pm 0.04$ & $0.7 \pm 0.04$ \\
$\mathrm{pH}$ & $5.5 \pm 0.10$ & $5.5 \pm 0.09$ \\
$\mathrm{TOC}(\%)$ & $24.3 \pm 2.54$ & $26.5 \pm 2.50$ \\
Flood depth (cm) & & \\
2012 & $61.6 \pm 5.7$ & $67.7 \pm 5.4$ \\
2013 & $53.7 \pm 4.9$ & $52.4 \pm 5.7$ \\
2014 & $63.5 \pm 5.3$ & $51.7 \pm 7.4$ \\
Spring flood duration (days) & & \\
2012 & $24.1 \pm 4.7$ & $26.4 \pm 2.6$ \\
2013 & $16.6 \pm 2.9$ & $16.6 \pm 2.4$ \\
2014 & $17.4 \pm 3.4$ & $13.9 \pm 2.1$ \\
\hline P values are given in Online Appendix 3. & & \\
\hline
\end{tabular}


richness in reaches with enhanced restoration. That is, although the average number of plant species per plot did not differ between restoration types (Figure 5), the minimum plant species richness per plot was higher for reaches with enhanced restoration $\left(\mathrm{LMM}, F_{1,9}=5.16, P=0.049\right.$, data not shown). Further, reaches with enhanced restoration contained slightly more species when looking at larger spatial scales. Three years after the cumulative number of species found in the 10 plots was significantly higher in reaches with enhanced restoration (LMM, $\left.F_{1,9}=11.51, P=0.008\right)$. Four years after restoration, the cumulative number of species was still consistently higher in enhanced reaches, but the difference was not significant and neither was the total number of plant species in the reach (Figure 5). There was no significant difference in aboveground plant and moss biomass between the two types of restored reaches 3 years after restoration (Online Appendix 3).

There was no significant difference in average plot cover of herb species, graminoid species, shrubs or trees between basic and enhanced reaches (Online Appendix 3). Four years after restoration, we found on average about five seedlings from natural origin per vegetation plot, which translates into a density of 10 seedlings $\mathrm{m}^{-2}$. There was a significant correlation between the numbers of seedlings in the third and fourth years after restoration in the reaches with enhanced restoration (Pearson's $r=0.61, P<0.001$ ), but not in the basic reaches (Pearson's $r=0.16, P=0.111$ ). Interestingly, in basic-restored reaches, seedling numbers decreased with elevation and thus increased with flooding frequency and duration $(r=-0.265, P=0.009)$, whereas these relation-

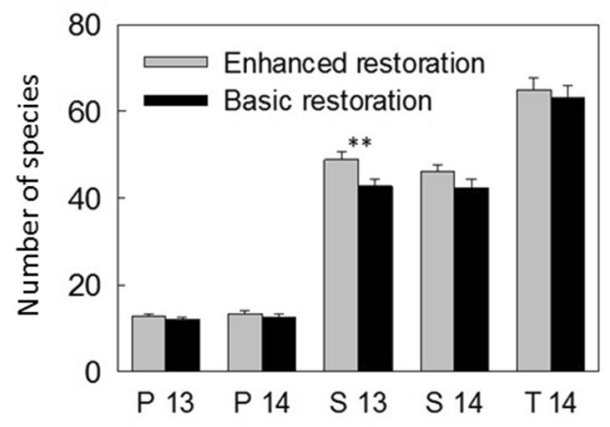

Figure 5. Mean number of species of riparian vegetation in individual plots $(P)$, the summed amount in the 10 plots $(S)$, and total amount in each reach $(T)$ in 2013 (13) and 2014 (14). Error bars indicate standard errors. Asterisks indicate statistical significance $(P<0.01)$. All $P$ values are given in Online Appendix 3. ships were absent in reaches with enhanced restoration (Pearson's $r=-0.093, P=0.36$ ).

Fish

Electrofishing yielded 1-47 individuals, representing 2-3 species, per study site before restoration and $1-81$ individuals, representing $1-4$ species, per study site 5 years after. In total, eight species of fish (S. trutta, C. gobio, S. salar, P. phoxinus, T. thymallus, E. lucius, L. lota, P. fluviatilis) and one species of lamprey (Lampetra planeri) were found across all sites. S. trutta occurred in all of the six streams studied and was the dominant species accounting for $76 \%$ and $77 \%$ of all individuals collected before restoration and 5 years after, respectively. The second most common species, $S$. salar, was only found in Beukabäcken, Mattjokkbäcken and Rågobäcken. The other species were only caught sporadically and in low numbers, whereby further statistical analyses were not conducted. None of the tested fish variables were significantly different between the year before restoration and 5 years after in either the basic or enhanced restoration reaches (Table 5).

\section{Discussion}

Several authors (Lake and others 2007; Palmer 2009; Palmer and others 2014b) have stressed the importance of basing stream restoration on ecological theory. So far, the majority of stream restoration projects have focused on channel morphology, adopting the theory that increasing heterogeneity favors species richness (Townsend and Hildrew 1994); fewer projects have tried to restore flow and sediment dynamics that are also major determinants of the biota and ecological processes (Palmer and others 2014b). Of course, channel modification also affects biota by changing hydraulics. For example, the flood pulse concept predicts that the simplification of the hydraulic regime that results from channelization will reduce species diversity (Junk and others 1989). In the Vindel River catchment, streams have been primarily impacted by channelization and there are no other impacts on the hydraulic regime except those caused by channel reconfiguration. As opposed to streams in more densely populated areas of the world, streams in this catchment have little to no impact of common stressors such as eutrophication, increased fine sediment inputs and flashy flow regimes due to high impervious land cover (Bernhardt and Palmer 2011; Woodward and others 2012), and available information suggests 


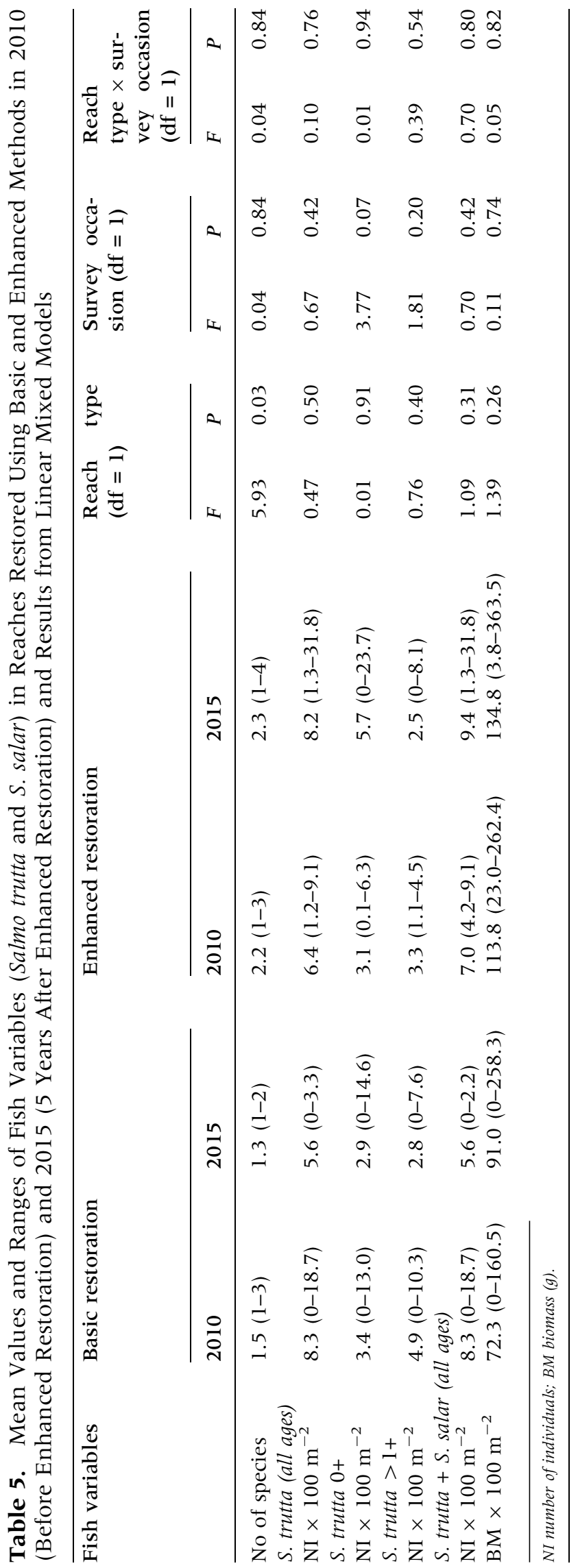


that the species pools remains largely intact (Nilsson and others 1994; Persson and Jonsson 1997). The restoration of the Vindel River tributaries was therefore built on the assumption that reconstruction of the local, physical environment in the streams would be the most important measure for stimulating biotic recovery, following the Field of Dreams hypothesis (Palmer and others 1997). Had the river been more impacted and with less intact species pools, the system could instead have been manipulated to maximize specific ecosystem services (Bullock and others 2011; Palmer and others 2014a), without any requirement to mimic more original conditions (Hobbs and others 2011).

Another assumption made by the practitioners responsible for the Vindel River restoration was that a complex channel configuration similar-but not necessarily identical-to pre-industrial conditions would be the best option for promoting biotic recovery owing to the fact that the industry (timber floating) has been terminated (Gardeström and others 2013) and given that there was little additional anthropogenic disturbance such as pollution. In regions with glacial depositional landforms, such as moraines, eskers, and drumlins, that are naturally rich in big boulders, it was not possible to restore channels back to their original conditions since much of the original coarse sediment had been blasted. This brought the idea to introduce enhanced restoration in line with the above-mentioned, growing consensus that increasing habitat complexity is critical in restoration (Loke and others 2015), by transporting large boulders from the uplands into the channel. Recent findings that restoration type, such as channel widening, remeandering and recreating instream structures, matters more than spatial restoration extent or time since restoration (Göthe and others 2016), provide further support for using improved restoration methods. Therefore, we hypothesized that enhanced restoration, increasing physical and hydraulic heterogeneity, would lead to higher biodiversity than would basic restoration.

\section{Abiotic Differences After Enhanced Restoration}

Our results clearly show that there was an increase in physical and hydraulic heterogeneity associated with reaches that had undergone enhanced restoration (Gardeström and others 2013; Polvi and others 2014; Nilsson and others 2015). As far as physical heterogeneity, we found an increase in bed sediment heterogeneity following enhanced restoration, in addition to the differences in the sediment distribution. Polvi and others (2014) also reported significant differences between the two types of restored reaches with respect to longitudinal and cross-sectional channel morphology. The large boulders that were placed into the channels as an enhanced restoration measure increased grain and form roughness, which reduced flow velocities, as measured by dimensionless flow velocity. The reduction in flow velocity was particularly evident at medium flow conditions.

Roughness increased significantly in enhanced restoration reaches after restoration. However, we also observed an increase in roughness in 2014 in the reaches with basic restoration at low flow conditions. Because the basic-restored reaches also have relatively coarse sediment compared to many gravel bed rivers, at low flow conditions, the cobbles and smaller boulders will contribute an equal amount of grain roughness as the larger boulders in the enhanced-restored reaches. At medium and higher flows, the large boulders in the enhanced reaches will occupy a larger percentage of the water column than the smaller boulders and cobbles in the basicrestored reaches. Therefore, at medium flows, we expected to see a larger effect of the enhanced restoration than at low flows on hydraulic heterogeneity measures. In these stream channels with coarse glacial legacy sediment, we do not expect a large amount of adjustment of boulders and other coarse sediment during the years following the enhanced restoration. This is in contrast to channels with finer sediment that are more dynamic during annual high flows, where geomorphic recovery may also require extra time after the actual restoration measures (Fryirs and Brierley 2000). Geomorphic adjustments in our semi-alluvial system will be caused by organization of the medium and fine sediment fractions (fine gravel to cobbles) around the coarse boulders, but this should not alter the overall sediment heterogeneity. In addition, many ice processes, particularly ice build-up and break-up, which are common in these streams (Lind and Nilsson 2015), can cause sediment transport (Turcotte and others 2011), with transport of boulders up to $2 \mathrm{~m}$ in diameter recorded in the Tana River in northern Finland (Lotsari and others 2015).

The main objective of the restoration of tributaries to the Vindel River was to enhance fish production (Gardeström and others 2013). Therefore, the focus was on redesigning the channel, like in most other stream restoration projects (Palmer and others $2014 \mathrm{~b}$ ), to favor spawning and feeding of fish (Gardeström and others 2013). However, it should not be forgotten that the increased retention capacity resulting from decreased flow veloci- 
ties and wider channels with increased lateral connections also serves other purposes, not least to reduce the intensity of floods caused by the extreme rain events that are expected to follow as a result of climate change (Kundzewicz and others 2014). This is an important side effect that speaks in favor of applying enhanced restoration at more sites. However, basic-restored sites also slow down flows, although to a smaller extent. Given that previous efforts using basic restoration covered many parts of the river system (Gardeström and others 2013), the increase in retention capacity following restoration should be substantial.

Because the enhanced restoration resulted in decreased velocities, it was expected that the production of anchor ice would also decrease. On the contrary, there was more anchor-ice production in enhanced reaches, but only if they were located far away from an upstream lake. Although the current velocity decreased, the turbulence might have increased since large trees were placed in the enhanced-restored reaches (Timalsina 2014). Increased turbulence around in-stream objects is important for transporting frazil ice from the surface to the bottom, thereby creating hotspots for production of anchor ice (Stickler and Alfredsen 2005). It could also be that the increased retention capacity of enhanced-restored reaches leads to more drifting frazil ice being captured, thus favoring anchor-ice production. In reaches close to lake outlets there was no anchor-ice production regardless of the type of restoration, whereas anchor-ice production increased in reaches that were further downstream from a lake and more geomorphically complex, which should translate into increased turbulence. The absence of anchor-ice formation close to lake outlets is explained by the temperature buffering capacity of the lakes that keeps the water from freezing. There are many other factors contributing to the presence of ice such as discharge, groundwater supply, temperature, and bottom substrate, which were not included in this study. Anchor ice has been shown to have impacts on the biota such as increasing riparian plant species richness while decreasing the potential for fish survival; this implies that the potential for ice formation should be included when planning restoration (Power 1993; Lind and others $2014 a, b)$.

\section{The Lack of Biotic Response and Its Potential Causes}

For obvious reasons, the physical alterations were visible more or less instantly after the enhanced restoration. The nature and rate of subsequent chemical and biotic changes, however, were more difficult to predict. We had expected that, eventually, the enhanced restoration measures would foster more biotically diverse reaches, but the speed and trajectory of these anticipated changes were impossible to predict. Given that restoration is a disturbance in itself, either a decrease or an increase in biotic variables could have been a possible outcome during the first few years following restoration (Zedler and Callaway 1999). Contrary to the physical differences between reaches subjected to basic and enhanced restoration, there were almost no biotic differences between reaches subjected to basic or enhanced restoration; species richness and abundance remained the same. Nor were there any chemical differences in the riparian soils between the two types of restored sites. Dietrich and others (2014) observed an increase in riparian soil fertility following basic restoration of channelized reaches suggesting that this initial restoration is more important than additional enhanced restoration of previously restored sites. Although chemical differences related to type of restoration may develop with time, at this stage, differences among streams were still larger than those between types of restored reaches. Therefore, we can assume that any general, biotic response to the enhanced restoration should be caused primarily by the observed increase in the heterogeneity of channel morphology and flow and ice patterns and not by chemical influence. Despite the physical and hydraulic changes, the biotic responses to enhanced restoration were practically nonexistent during the course of this study. Does this mean that our paper will add to the quite abundant literature that report null results following restoration, without being able to explain the outcome? Before responding to this question, we point out that attempts to predict more final results can be centered in either time- or dispersal-related factors. In reality, these factors are intertwined, but for clarity's sake we here discuss them separately.

As regards time, there are reasons to believe that, eventually, the biotic response of the enhanced reaches will be stronger than in the basic reaches. For example, although our vegetation survey indicated that reaches with basic and enhanced restoration were practically the same with no differences in vegetation cover or composition, there was a slight tendency for a higher species richness in enhanced reaches. This latter observation was made although the basic restoration took place about $5-8$ years before the enhanced restoration and may indicate a rise in species immigration 
following the increase in morphological heterogeneity in enhanced reaches. If so, it would be in line with the augmented propagule retention observed by Engström and others (2009) following (basic) restoration of channelized stream reaches. Provided that the regional species pool is reasonably diverse and not dispersal-limited (Brederveld and others 2011; Sundermann and others 2011; Tonkin and others 2014), due to increased retention capacity, enhanced reaches may become more species rich than basic reaches given more time. The higher seedling numbers found in enhanced reaches support this reasoning. However, most riparian plants need a high spring flood to be caught by the flowing water and be transported, and spring flood intensity may vary considerably among years (Balke and others 2014). The fact that different immigration times may result in different floras (Sarneel and others 2016) makes predictions difficult. Another complicating factor is that many plant species in northern regions have a poor or infrequent seed production and may not be able to disperse any seeds when an opportunity arises (Molau and Larsson 2000). Therefore, even if our observations may suggest an ongoing differentiation between the restored reach types, it may take long for plants to establish in newly restored sites, even though these sites may be perfectly suitable for them (Hanski 2000).

Predictions of dispersal success in heterogeneous landscapes are challenging because many factors need to work together for an effective immigration of plant propagules to occur (Gustafson and Gardner 1996; Mouquet and Loreau 2003). First, turbulent reaches have a flora that is largely different from that of tranquil reaches as well as uplands (Nilsson and others 1994, 2010). Given that turbulent reaches can be situated quite far apart, and the chances for a floating plant propagule to be dispersed from an upstream turbulent reach to a restored turbulent reach further downstream-and be deposited there-are rather small simply due to distance. For example, lakes are common in these systems and lakes-as well as other tranquil, wide water bodies-are efficient seed traps (Brown and Chenoweth 2008). When a plant propagule is finally stranded at a restored site, factors such as water levels, soil moisture and temperature need to be favorable to promote establishment (Merritt and others 2010), and such conditions are not likely to occur every year (Balke and others 2014). For example, Riis (2008) studied dispersal and colonization of aquatic plants in a stream reach in Denmark and concluded that primary colonization was the major factor constraining vegetation development in restored (vegetation-free) sites. Given these circumstances, the floristic development of enhanced-restored reaches may not be predictable simply based on reach-scale heterogeneity but requires an analysis of the landscape context for its understanding. For example, an enhanced-restored reach close to an upstream rapid section may encounter a much more favorable recovery than a similar reach downstream of a lake. To compensate for such obstacles, many stream restoration projects therefore introduce propagules to enhance vegetation recovery (Kiehl and others 2010).

The data on salmonid fish numbers and biomass were variable but - as for plants-did not show any general differences between the start and end of the project or with respect to whether sites were restored by basic or enhanced methods. There are several possible reasons for this lack of response. First, the scale of restoration could have been too small to lead to a general response of the fish population. Salmo trutta, which was the dominant salmonid species, typically has large home ranges and extended migration within and between tributary streams is common (Carlsson and others 2004; Palm and others 2009). Therefore, the reaches subjected to enhanced restoration were most likely too short to have a direct effect on the fish (but see Gowan and Fausch 1996; Palm and others 2009). Had entire subcatchments been restored using enhanced methods, it is more likely that the fish community would have shown a stronger response. For example, Roni and others (2010) found that all the available habitat would need to be restored to reach $95 \%$ certainty of achieving $25 \%$ more smolt production (that is, downstream migrating juveniles) for two species of Pacific salmon (Oncorhynchus kisutch and O. mykiss). A second possible reason is that enhanced restoration could have made electrofishing more difficult by the increased wetted area of the channels (Kolz 2006). In other words, it cannot be excluded that there were fish responses but that they were missed because of methodological shortcomings (compare Nilsson and others 2015). Third, the main food resource for $S$. trutta-benthic invertebrates-may not yet have recovered well enough to feed a larger S. trutta population (Muotka and others 2002; Louhi and others 2011). Fourth, a higher amount of anchor-ice accumulation in enhanced reaches may cause freezing of fish eggs and displacement, habitat exclusion and increased movement of fish, which can cause direct mortality (Power 1993; Weber and others 2013). A fifth reason could be added, that if fish populations, that is, the actual 
parental stocks, are small after restoration, they may require many years to recover to their potential sizes (Albanese and others 2009).

\section{ConClusions}

To conclude, our follow-up study showed that, although enhanced restoration changed the physical and hydraulic conditions of previously restored stream reaches, their biota had not responded 5 years after this restoration. This finding is consistent with other studies that have failed to find biotic responses of increasing physical heterogeneity in restored stream reaches (Jähnig and others 2010; Palmer and others 2010; Nilsson and others 2015). However, when evaluating this study it is important to keep in mind that we compared two types of restored reaches, restored during different time periods, and both of which are improved compared to channelized reaches (Gardeström and others 2013; Hasselquist and others 2015; Nilsson and others 2015). Had we compared still channelized reaches with enhanced reaches a different biotic outcome might have been found (for example, Helfield and others 2007). Hasselquist and others (2015) observed that riparian vegetation needed 25 years or more to recover solely from restoration disturbance, implying that any further recovery would take even longer. This suggests that many years may remain until the biotic effects of enhanced restoration actions can be accurately evaluated, so the size of a potential "species credit" (that is, species to come, Hanski 2000) is yet unknown.

Do our biotic results mean that this is yet another attempt at stream restoration with null results? We propose that our results in this unique environment, without catchment-scale disturbances and with naturally geomorphic complex channel structures, lend support to three important takehome messages for restoration. First, restoration is a disturbance in itself and the disturbance by restoring basic-restored reaches once more is negligible after 5 years, second, immigration potential varies across catchments and may form an important bottleneck, and third, recovery rate is slow in boreal streams. A landscape-scale approach, taking into consideration other impacts in the catchment, such as migration barriers and lack of source populations, is necessary in planning restoration and for judging success (for example, Simenstad and others 2006; Lake and others 2007; Nilsson and others 2015). Seed dispersal is complicated by a number of factors: source populations are at other similar types of reaches that can be separated by lakes, a high spring flood is necessary for efficient seed dispersal and appropriate conditions for seed production are required to make dispersal possible. Similarly, connectivity of sites and spatial extent of restoration need to be sufficient to enable migratory fish populations to recover. In some ways, a landscape-scale approach has been taken in the case of basic restoration, for which most turbulent reaches in the tributaries have been restored, many side channels have been opened up and many migration obstacles, such as splash dams, have been removed. Any attempts to strengthen source populations by actively introducing organisms have however not been made. Although studies on the effects of restoration may seem only worth sharing if they provide positive results, we encourage critical examination of restoration results regardless of the outcome in order to further explore how to plan future restoration projects. Nilsson and others (2016) demonstrate that there is evaluation in all phases of ecological restoration and call for thorough documentation of evaluation steps to make such planning possible.

Thus, for now we can conclude that the enhanced restoration did not exert negative impacts on biota, and therefore future restoration managers may choose to adopt the enhanced restoration methods directly, rather than using a stepwise approach, thereby limiting the effect of disturbance by the restoration activities themselves (such as by machines). A one-time (enhanced) restoration effort will also be cheaper than two (stepwise) restoration events. The climatic constraints of the study area (short growing seasons) mean that recovery is likely to be slow. However, the very low percentage of alien, invasive species in the area (Dynesius and others 2004), and the limited pressures of other anthropogenic activities, mean that it should be possible to await recolonization without further measures. This provides an ideal opportunity for monitoring and studying natural recovery and colonization processes. If monitoring and evaluations of restoration results are required by funding agencies, there are usually set budgets. The most effective way to administer such a resource for follow-up work would be low-intensity monitoring over several decades instead of high-intensity monitoring during only the first few years following restoration. Such a long-term strategy, located to encompass the varying conditions within catchments, would reduce the risk for inaccurate conclusions about the success of a restoration and strengthen the influence of evaluations when future restoration actions are planned (Nilsson and others 2016). Finally, we would like to recall that 
the slow payoff of restoration is a very important reason to protect rivers from future damage.

\section{ACKNOWLEDGEMENTS}

This project was funded by the European Commission through their LIFE Nature program and by the Swedish Agency for Marine and Water Management, the County Administration Board of Västerbotten, Umeå University, Swedish University of Agricultural Sciences, Ume/Vindel River Fishery Advisory Board, and the municipalities of Arjeplog, Sorsele, Lycksele, Vännäs, Vindeln and Umeå. We also acknowledge the strategic theme Sustainability of Utrecht University, subtheme Water, Climate, and Ecosystems for funding (to JMS). Two reviewers provided useful comments on the manuscript.

\section{OPEN ACCESS}

This article is distributed under the terms of the Creative Commons Attribution 4.0 International License (http://creativecommons.org/licenses/by/ 4.0/), which permits unrestricted use, distribution, and reproduction in any medium, provided you give appropriate credit to the original author(s) and the source, provide a link to the Creative Commons license, and indicate if changes were made.

\section{REFERENCES}

Acuna V, Díez JR, Flores L, Meleason M, Elosegi A. 2013. Does it make economic sense to restore rivers for their ecosystem services? J Appl Ecol 50:988-97.

Albanese B, Angermeier PL, Peterson JT. 2009. Does mobility explain variation in colonisation and population recovery among stream fishes? Freshw Biol 54:1444-60.

Alexander GG, Allan JD. 2007. Ecological success in stream restoration: case studies from the Midwestern United States. Environ Manage 40:245-55.

Aronson J, Alexander S. 2013. Ecosystem restoration is now a global priority: time to roll up our sleeves. Restor Ecol 21:2936.

Aviron S, Herzog F, Klaus I, Schupbach B, Jeanneret P. 2011. Effects of wildflower strip quality, quantity, and connectivity on butterfly diversity in a Swiss arable landscape. Restor Ecol 19:500-8.

Baker DW. 2009. Land use effects on physical habitat and nitrate uptake in small streams of the central Rocky Mountain region. PhD Dissertation, Fort Collins: Colorado State University.

Balke T, Herman PMJ, Bouma TJ. 2014. Critical transitions in disturbance-driven ecosystems: identifying Windows of Opportunity for recovery. J Ecol 102:700-8.

Bernhardt ES, Palmer MA. 2011. River restoration: the fuzzy logic of repairing reaches to reverse catchment scale degradation. Ecol Appl 21:1926-31.

Bernhardt ES, Palmer MA, Allan JD, Alexander G, Barnas K, Brooks S, Carr J, Clayton S, Dahm C, Follstad-Shah J, Galat D,
Gloss S, Goodwin P, Hart D, Hassett B, Jenkinson R, Katz S, Kondolf GM, Lake PS, Lave R, Meyer JL, O'Donnell TK, Pagano L, Powell B, Sudduth E. 2005. Synthesizing U.S. river restoration efforts. Science 308:636-7.

Bernhardt ES, Sudduth EB, Palmer MA, Allan JD, Meyer JL, Alexander G, Follastad-Shah J, Hassett B, Jenkinson R, Lave R, Rumps J, Pagano L. 2007. Restoring rivers one reach at a time: results from a survey of U.S. river restoration practitioners. Restor Ecol 15:482-93.

Brederveld RJ, Jähnig SC, Lorenz AW, Brunzel S, Soons MB. 2011. Dispersal as a limiting factor in the colonization of restored mountain streams by plants and macroinvertebrates. J Appl Ecol 48:1241-50.

Briggs D. 1977. Sediments: sources and methods in geography. London: Butterworths.

Brown RL, Chenoweth J. 2008. The effect of Glines Canyon Dam on hydrochorous seed dispersal in the Elwha River. Northwest Science 82:197-209.

Bullock JM, Aronson J, Newton AC, Pywell RF, Rey-Benayas JM. 2011. Restoration of ecosystem services and biodiversity: conflicts and opportunities. Trends Ecol Evol 26:541-9.

Carlsson J, Aarestrup K, Nordwall F, Näslund I, Eriksson T, Carlsson JEL. 2004. Migration of landlocked brown trout in two Scandinavian streams as revealed from trap data. Ecol Freshw Fish 13:161-7.

Conlisk E, Motheral S, Chung R, Wisinski C, Endress B. 2014. Using spatially-explicit population models to evaluate habitat restoration plans for the San Diego cactus wren (Campylorhynchus brunneicapillus sandiegensis). Biol Conserv 175:4251.

Crouzeilles R, Prevedello JA, Figueiredo MSL, Lorini ML, Grelle CEV. 2014. The effects of the number, size and isolation of patches along a gradient of native vegetation cover: how can we increment habitat availability? Landscape Ecol 29:479-89.

Dietrich AL, Lind L, Nilsson C, Jansson R. 2014. The use of phytometers for evaluating restoration effects on riparian soil fertility. J Environ Qual 43:1916-25.

Dynesius M, Jansson R, Johansson ME, Nilsson C. 2004. Intercontinental similarities in riparian-plant diversity and sensitivity to river regulation. Ecol Appl 14:173-91.

Dynesius M, Nilsson C. 1994. Fragmentation and flow regulation of river systems in the northern third of the world. Science 266:753-62.

Elosegi A, Diez J, Mutz M. 2010. Effects of hydromorphological integrity on biodiversity and functioning of river ecosystems. Hydrobiologia 657:199-215.

Engström J, Nilsson C, Jansson R. 2009. Effects of stream restoration on dispersal of plant propagules. J Appl Ecol 46:397-405.

Fryirs K, Brierley G. 2000. A geomorphic approach to the identification of river recovery potential. Phys Geogr 21:24477.

Fryirs K, Chessman B, Rutherfurd I. 2013. Progress, problems and prospects in Australian river repair. Mar Freshw Res 64:642-54.

Gardeström J, Holmqvist D, Polvi LE, Nilsson C. 2013. Demonstration restoration measures in tributaries of the Vindel river catchment. Ecology and Society 18(3):8. doi:10.5751/ES05609-180308.

Göthe E, Timmermann A, Januschke K, Baattrup-Pedersen A. 2016. Structural and functional responses of floodplain vegetation to stream restoration. Hydrobiologia 769:79-92. 
Gowan C, Fausch KK. 1996. Long-term demographic responses of trout populations to habitat manipulation in six Colorado streams. Ecol Appl 6:931-46.

Gustafson EJ, Gardner RH. 1996. The effect of landscape heterogeneity on the probability of patch colonization. Ecology 77:94-107.

Hanski I. 2000. Extinction debt and species credit in boreal forests: modelling the consequences of different approaches to biodiversity conservation. Ann Zool Fenn 37:271-80.

Harms RS, Hiebert RD. 2006. Vegetation response following invasive tamarisk (Tamarix spp.) removal and implications for riparian restoration. Restor Ecol 14:461-72.

Hasselquist EM, Nilsson C, Hjältén J, Jørgensen D, Lind L, Polvi LE. 2015. Time for recovery of riparian plants in restored northern Swedish streams: a chronosequence study. Ecol Appl 25:1373-89.

Helfield JM, Capon SJ, Nilsson C, Jansson R, Palm D. 2007. Restoration of rivers used for timber floating: effects on riparian plant diversity. Ecol Appl 17:840-51.

Hobbs RJ, Hallett LM, Ehrlich PR, Mooney HA. 2011. Intervention ecology: applying ecological science in the twentyfirst century. Bioscience 61:442-50.

Jähnig SC, Brabec K, Buffagni A, Erba S, Lorenz AW, Ofenbock T, Verdonschot PFM, Hering D. 2010. A comparative analysis of restoration measures and their effects on hydromorphology and benthic invertebrates in 26 central and southern European rivers. J Appl Ecol 47:671-80.

Jiménez MN, Spotswood EN, Cañadas EM, Navarro FB. 2015. Stand management to reduce fire risk promotes understorey plant diversity and biomass in a semi-arid Pinus halepensis plantation. Appl Veg Sci 18:467-80.

Junk WJ, Bayley PB, Sparks RE. 1989. The flood pulse concept in river-floodplain systems. Can Spec Publ Fish Aquat Sci 106:110-27.

Kail J, Hering D, Muhar S, Gerhard M, Preis S. 2007. The use of large wood in stream restoration: experiences from 50 projects in Germany and Austria. J Appl Ecol 44:1145-55.

Kiehl K, Kirmer A, Donath TW, Rasran L, Hölzel N. 2010. Species introduction in restoration projects: evaluation of different techniques for the establishment of semi-natural grasslands in Central and Northwestern Europe. Basic Appl Ecol 11:285-99.

Kolz AL. 2006. Electrical conductivity as applied to electrofishing. Trans Am Fish Soc 135:509-18.

Kondolf GM, Micheli ER. 1995. Evaluating stream restoration projects. Environ Manage 19:1-15.

Krause B, Culmsee H. 2013. The significance of habitat continuity and current management on the compositional and functional diversity of grasslands in the uplands of Lower Saxony, Germany. Flora 208:299-311.

Kundzewicz ZW, Kanae S, Seneviratne SI, Handmer J, Nicholls N, Peduzzi P, Mechler R, Bouwer LM, Arnell N, Mach K, Muir-Wood R, Brakenridge GR, Kron W, Benito G, Honda Y, Takahashi K, Sherstyukov B. 2014. Flood risk and climate change: global and regional perspectives. Hydrol Sci J 59:1-28.

Lake PS, Bond N, Reich P. 2007. Linking ecological theory with stream restoration. Freshw Biol 52:597-615.

Lambeck K, Smither C, Johnston P. 1998. Sea-level change, glacial rebound and mantle viscosity for northern Europe. Geophys J Int 134:102-44.

Lepori F, Gaul D, Palm D, Malmqvist B. 2006. Food-web responses to restoration of channel heterogeneity in boreal streams. Can J Fish Aquat Sci 63:2478-86.
Lepori F, Palm D, Brännäs E, Malmqvist B. 2005. Does restoration of structural heterogeneity in streams enhance fish and macroinvertebrate diversity? Ecol Appl 15:2060-71.

Lind L, Nilsson C. 2015. Vegetation patterns in small boreal streams relate to ice and winter floods. J Ecol 103:431-40.

Lind L, Nilsson C, Polvi LE, Weber C. 2014a. The role of ice dynamics in shaping vegetation in flowing waters. Biol Rev 89:791-804.

Lind L, Nilsson C, Weber C. 2014b. Effects of ice and floods on vegetation in streams in cold regions: implications for climate change. Ecol Evol 4:4173-84.

Loke LHL, Ladle RJ, Bouma TJ, Todd PA. 2015. Creating complex habitats for restoration and reconciliation. Ecol Eng 77:307-13.

Lotsari E, Wang Y, Kaartinen H, Jaakkola A, Kukko A, Vaaja M, Hyyppä H, Hyyppä J, Alho P. 2015. Gravel transport by ice in a subarctic river from accurate laser scanning. Geomorphology 246:113-22.

Louhi P, Mykrä H, Paavola R, Huusko A, Vehanen T, MäkiPetäys A, Muotka T. 2011. Twenty years of stream restoration in Finland: little response by benthic macroinvertebrate communities. Ecol Appl 21:1950-61.

Merritt DM, Nilsson C, Jansson R. 2010. Consequences of propagule dispersal and river fragmentation for riparian plant community diversity and turnover. Ecol Monogr 80:609-26.

Molau U, Larsson EL. 2000. Seed rain and seed bank along an alpine altitudinal gradient in Swedish Lapland. Can J Bot 78:728-47.

Mouquet N, Loreau M. 2003. Community patterns in sourcesink metacommunities. Am Nat 162:544-57.

Muotka T, Paavola R, Haapala A, Novikmec M, Laasonen P. 2002. Long-term recovery of stream habitat structure and benthic invertebrate communities from in-stream restoration. Biol Conserv 105:243-53.

Naiman RJ, Décamps H. 1997. The ecology of interfaces: riparian zones. Annu Rev Ecol Syst 28:621-58.

Naiman RJ, Décamps H, McClain ME. 2005. Riparia: ecology, conservation, and management of streamside communities. New York: Elsevier.

Nakagawa S, Schielzeth H. 2010. Repeatability for Gaussian and non-Gaussian data: a practical guide for biologists. Biol Rev 85:935-56.

Nilsson C, Aradottir AL, Hagen D, Halldórsson G, Høegh K, Mitchell RJ, Raulund-Rasmussen K, Svavarsdóttir K, Tolvanen A, Wilson SD. 2016. Evaluating the process of ecological restoration. Ecol Soc 21 (1):41. doi:10.5751/ES-08289-210141.

Nilsson C, Brown RL, Jansson R, Merritt DM. 2010. The role of hydrochory in structuring riparian and wetland vegetation. Biol Rev 85:837-58.

Nilsson C, Ekblad A, Dynesius M, Backe S, Gardfjell M, Carlberg B, Hellqvist S, Jansson R. 1994. Comparison of species richness and traits of riparian plants between a main river channel and its tributaries. J Ecol 82:281-95.

Nilsson C, Lepori F, Malmqvist B, Törnlund E, Hjerdt N, Helfield JM, Palm D, Östergren J, Jansson R, Brännäs E, Lundqvist H. 2005a. Forecasting environmental responses to restoration of rivers used as log floatways: an interdisciplinary challenge. Ecosystems 8:779-800.

Nilsson C, Reidy CA, Dynesius M, Revenga C. 2005b. Fragmentation and flow regulation of the world's large river systems. Science 308:405-8.

Nilsson C, Polvi LE, Gardeström J, Hasselquist EM, Lind L, Sarneel JM. 2015. Riparian and in-stream restoration of 
boreal streams and rivers: success or failure? Ecohydrology 8:753-64.

Nungesser M, Saunders C, Coronado-Molina C, Obeysekera J, Johnson J, McVoy C, Benscoter B. 2015. Potential effects of climate change on Florida's Everglades. Environ Manage 55:824-35.

Palm D, Brännäs E, Nilsson K. 2009. Predicting site-specific overwintering of juvenile brown trout (Salmo trutta) using a habitat suitability index. Can J Fish Aquat Sci 66:540-6.

Palm D, Brännäs E, Lepori F, Nilsson K, Stridsman S. 2007. The influence of spawning habitat restoration on juvenile brown trout (Salmo trutta) density. Can J Fish Aquat Sci 64:509-15.

Palmer MA. 2009. Reforming watershed restoration: science in need of application and applications in need of science. Estuaries Coasts 32:1-17.

Palmer MA, Ambrose RF, Poff NL. 1997. Ecological theory and restoration ecology. Restor Ecol 5:291-300.

Palmer MA, Filoso S, Fanelli RM. 2014a. From ecosystems to ecosystem services: stream restoration as ecological engineering. Ecol Eng 65:62-70.

Palmer MA, Hondula KL, Koch BJ. 2014b. Ecological restoration of streams and rivers: shifting strategies and shifting goals. Annu Rev Ecol Evol Syst 45:247-69.

Palmer MA, Menninger HL, Bernhardt E. 2010. River restoration, habitat heterogeneity and biodiversity: a failure of theory or practice? Freshw Biol 55(Supplement 1):205-22.

Pander J, Geist J. 2013. Ecological indicators for stream restoration success. Ecol Ind 30:106-18.

Persson PE, Jonsson M. 1997. Nationalälv, naturreservat: Vindelälven. Umeå: County Administrative Board of Västerbotten.

Pinheiro J, Bates D, DebRoy S, Sarkar D, R Core Team. 2015. nlme: linear and nonlinear mixed effects models. $\mathrm{R}$ package version 3.1-120. URL: http://CRAN.R-project.org/package=nlme.

Polvi LE, Nilsson C, Hasselquist EM. 2014. Potential and actual geomorphic complexity of restored headwater streams in northern Sweden. Geomorphology 210:98-118.

Power G. 1993. Estimating production, food supplies and consumption by juvenile Atlantic salmon (Salmo salar). Can Spec Publ Fish Aquat Sci 118:163-74.

Prowse TD. 1995. River ice processes. In: Beltaos S, Ed. River ice jams. Highlands Ranch, Colorado: Water Resources Publications, LLC. p 29-70.

Riis T. 2008. Dispersal and colonisation of plants in lowland streams: success rates and bottlenecks. Hydrobiologia 596:341-51.

RiverWiki. 2014. Restoring Europe's rivers. URL: https:// restorerivers.eu/wiki/index.php?title=Main_Page. Accessed 16 September 2015.

Roni P, Pess G, Beechie T, Morley S. 2010. Estimating changes in coho salmon and steelhead abundance from watershed restoration: how much restoration is needed to measurably increase smolt production? North Am J Fish Manag 30:1469-84.

Rosenfeld J, Hogan D, Palm D, Lundquist H, Nilsson C, Beechie TJ. 2011. Contrasting landscape influences on sediment supply and stream restoration priorities in northern Fennoscandia (Sweden and Finland) and coastal British Columbia. Environ Manage 47:28-39.

Sarneel JM, Kardol P, Nilsson C. 2016. The importance of priority effects for riparian plant community dynamics. J Veg Sci 27:658-67.

Simenstad C, Reed D, Ford M. 2006. When is restoration not? Incorporating landscape-scale processes to restore self-sus- taining ecosystems in coastal wetland restoration. Ecol Eng $26: 27-39$

SMHI. 2010. Sveriges vattendrag. Faktablad nr 44. Swedish Meteorological and Hydrological Institute, Norrköping, Sweden.

SMHI. 2013. URL: http://www.smhi.se/klimatdata.

Stickler M, Alfredsen KT. 2005. Factors controlling anchor ice formation in two Norwegian rivers. In: Proceedings of the 13th workshop on the hydraulics of ice covered rivers. CGU HS Committee on River Ice Processes and the Environment, Hanover, New Hampshire.

Stickler M, Alfredsen KT. 2009. Anchor ice formation in streams: a field study. Hydrol Process 23:2307-15.

Suding KN. 2011. Toward an era of restoration in ecology: successes, failures and opportunities ahead. Annu Rev Ecol Evol Syst 42:465-87.

Sundermann A, Stoll A, Haase P. 2011. River restoration success depends on the species pool of the immediate surroundings. Ecol Appl 21:1962-71.

Tews J, Brose U, Grimm V, Tielborger K, Wichmann MC, Schwager M, Jeltsch F. 2004. Animal species diversity driven by habitat heterogeneity/diversity: the importance of keystone structures. J Biogeogr 31:79-92.

Timalsina N. 2014. Ice conditions in Norwegian rivers regulated for hydropower: an assessment in the current and future climate. Trondheim, Norway: NTNU.

Tonkin JD, Stoll S, Sundermann A, Haase P. 2014. Dispersal distance and the pool of taxa, but not barriers, determine the colonisation of restored river reaches by benthic invertebrates. Freshw Biol 59:1843-55.

Törnlund E, Östlund L. 2002. The floating of timber in northern Sweden: construction of floatways and transformation of rivers. Environmental History 8:85-106.

Townsend CR, Hildrew AG. 1994. Species traits in relation to a habitat templet for river systems. Freshw Biol 31:265-75.

Turcotte B, Morse B. 2013. A global river ice classification model. J Hydrol 507:134-48.

Turcotte B, Morse B, Bergeron NE, Roy AG. 2011. Sediment transport in ice-affected rivers. J Hydrol 409:561-77.

van Dijk J, Stroetenga M, van Bodegom PM, Aerts R. 2007. The contribution of rewetting to vegetation restoration of degraded peat meadows. Appl Veg Sci 10:315-24.

Ward JV, Tockner K. 2001. Biodiversity: towards a unifying theme for river ecology. Freshw Biol 46:807-19.

Weber C, Nilsson C, Lind L, Alfredsen K, Polvi LE. 2013. Winter disturbance and riverine fish in temperate and cold regions. Bioscience 63:199-210.

Wohl E, Lane SN, Wilcox AC. 2015. The science and practice of river restoration. Water Resour Res 51:5974-97.

Woodward G, Gessner MO, Giller PS, Gulis V, Hladyz S, Lecerf A, Malmqvist B, McKie BG, Tiegs SD, Cariss H, Dobson M, Elosegi A, Ferreira V, Graça MAS, Fleituch T, Lacoursière JO, Nistorescu M, Pozo J, Risnoveanu G, Schindler M, Vadineanu A, Vought LB-M, Chauvet E. 2012. Continental-scale effects of nutrient pollution on stream ecosystem functioning. Science 336:1438-40.

Zedler JB. 2010. How frequent storms affect wetland vegetation: a preview of climate-change impacts. Front Ecol Environ 8:540-7.

Zedler JB, Callaway JC. 1999. Tracking wetland restoration: do mitigation sites follow desired trajectories? Restor Ecol 7:69-73.

Zippin C. 1956. An evaluation of the removal method of estimating animal populations. Biometrics 12:163-89. 